Respiration 2010;80:353-354

DOI: 10.1159/000319014

\section{Resolution of Respiratory Failure with Radiotherapy in Myelofibrosis}

\author{
Kadri Atay ${ }^{\mathrm{a}}$, Fatih Tufan ${ }^{\mathrm{a}}$, Yusuf Kayar ${ }^{\mathrm{a}}$, Tuncay Sahutoglu ${ }^{\mathrm{a}}$, \\ Bulent Saka ${ }^{a}$, Reyhan Kucukkaya ${ }^{\mathrm{a}}$, Mustafa Erelel ${ }^{\mathrm{b}}$, \\ Cemil Tascioglua
}

Departments of alnternal Medicine and ${ }^{b}$ Respiratory Medicine, Istanbul Medical Faculty, Istanbul University, Istanbul, Turkey

Splenomegaly can be an independent cause of morbidity in patients with idiopathic myelofibrosis (IMF). Massive splenomegaly can lead to early satiety, bloating, splenic pain, portal hypertension and cytopenias [1]. Radiotherapy (RT) had been used either for symptomatic relief and extramedullary hematopoiesis in patients with IMF $[1,2]$. While RT is generally effective in these indications, the effects may be transient and patients may experience significant myelosuppression which potentially causes significant morbidity $[1,2]$. Respiratory failure in patients with IMF may be due to interstitial or pleural extramedullary hematopoiesis or severe infections. To our knowledge, there is no report of splenomegaly-induced hypoxemic hypercapnic respiratory failure resolving with splenic RT.

A 61-year-old male patient presented with shortness of breath and severe peripheral edema. He had a diagnosis of IMF 6 years ago and was on hydroxyurea treatment for 4 years. During the last 3 months he had had these symptoms progressively and he received frequent (approximately once a week) blood transfusions for severe anemia. Physical examination revealed paleness, bilateral pretibial severe pitting edema, jugular venous distention, tachypnea, dullness to percussion in the right hemithorax, bilateral basilar coarse crackles, hepatomegaly $(10 \mathrm{~cm}$ below the right costal margin) and massive splenomegaly which reached the pelvis and right lumbar region. Laboratory analysis revealed normal renal functions, electrolytes and liver enzymes. Lactate dehydrogenase $(2,838 \mathrm{U} / \mathrm{l}$, normal value $<450)$ and uric acid $(10 \mathrm{mg} / \mathrm{dl})$ levels were elevated. The erythrocyte sedimentation rate was 32 $\mathrm{mm} / \mathrm{h}$ and the C-reactive protein level was $10 \mathrm{mg} / \mathrm{l}$. Complete blood count showed normocytic anemia (hemoglobin $6.8 \mathrm{~g} / \mathrm{dl}$ ), leukocytosis (white blood cells $28,800 / \mathrm{mm}^{3}$, neutrophils $13,000 /$ $\mathrm{mm}^{3}$ ) and a normal platelet value $\left(176,000 / \mathrm{mm}^{3}\right)$. Arterial blood gas analysis showed hypoxemia $\left(\mathrm{pO}_{2} 54 \mathrm{~mm} \mathrm{Hg}, \mathrm{SO}_{2} 83 \%\right)$, hypercapnia $\left(\mathrm{pCO}_{2} 51 \mathrm{~mm} \mathrm{Hg}\right)$, a $\mathrm{pH}$ of 7.40 and a bicarbonate level of $30 \mathrm{mEq} / \mathrm{l}$. On admission, the patient was given intravenous diuretic therapy which resulted in polyuria and resolution of pe- ripheral edema. Two liters of nasal oxygen resulted in normalization of oxygen saturation (96\%) but headache and somnolence developed. Control arterial blood gas analysis showed a $\mathrm{pCO}_{2}$ level of $75 \mathrm{~mm} \mathrm{Hg}$. Oxygen treatment was stopped. Bi-level positive airway pressure treatment was begun. Pleural effusion was transudative and had a low cell count; smear from centrifuged pleural fluid showed scarce erythroblasts. Six hundred milliliters of pleural fluid was drained. Echocardiography revealed severe pulmonary arterial hypertension $(104 \mathrm{~mm} \mathrm{Hg})$, normal left ventricle systolic functions, left ventricle hypertrophy, degenerative mild aortic stenosis and moderate mitral valve insufficiency. Ultrasound of the abdomen confirmed hepatomegaly and splenomegaly and revealed ascites. Ascitic fluid analysis showed that ascites were of a portal hypertensive type and contained precursors of myeloid and erythroid cell lines. Despite adjustment of inspiratory and expiratory pressures of bi-level positive airway pressure device and delivered oxygen concentration, severe hypercapnia persisted (above $65 \mathrm{~mm} \mathrm{Hg}$ ). Control arterial blood gas analyses in ambient air showed that hypoxemia persisted in the following days. There was no significant congestion, rales, pleural effusion or ascites along with respiratory failure. At this time, restriction of diaphragmatic movement by massive splenomegaly was considered an important cause of respiratory failure. Splenic RT was begun and resulted in significant regression of splenic volume. One week after the beginning of RT, respiratory distress resolved and control blood gas analysis in ambient air showed normalization of $\mathrm{pO}_{2}(76 \mathrm{~mm} \mathrm{Hg})$ and near normalization of $\mathrm{pCO}_{2}(51 \mathrm{~mm} \mathrm{Hg})$. The leukocyte and $\mathrm{pCO}_{2}$ levels before and during $\mathrm{RT}$ are listed in table 1 . This was consistent with the resolution of respiratory failure but with persistence of alveolar hypoventilation. After 7 cycles of RT, severe pancytopenia developed. With supportive measures and filgrastim therapy, cytopenias resolved without a serious complication. However, the severity of cytopenias increased after RT and the patient needed more frequent red blood cell and platelet transfusions.

Table 1. Levels of leukocyte and carbon dioxide pressures before, during and after RT

\begin{tabular}{lrllllllll}
\hline $\begin{array}{l}\text { Days } \\
\text { of RT }\end{array}$ & -3 & -1 & 0 & 1 & 3 & 5 & $\begin{array}{l}7 \text { (last } \\
\text { day of RT) }\end{array}$ \\
\hline WBC & 9,600 & 9,880 & 8,850 & 7,180 & 4,450 & 3,200 & 1,210 & 700 \\
pCO $_{2}$ & 68 & 69 & 65 & 67 & 67 & 66 & & 51 \\
\hline
\end{tabular}

$\mathrm{WBC}=$ White blood cell count

\section{KARGER}

Fax +41 613061234 E-Mail karger@karger.ch www.karger.com
(C) 2010 S. Karger AG, Basel

0025-7931/10/0804-0353\$26.00/0 
Although this patient had several etiologic factors for respiratory failure including congestive heart failure, pleural effusion and ascites, hypoxemia and hypercapnia persisted even more than 1 week after these factors resolved. Recently, pulmonary arterial hypertension associated with chronic recurrent thromboembolism or myeloid metaplasia was reported in patients with myeloproliferative diseases [3]. These factors might have been important in our patient as well, because he had severe pulmonary arterial hypertension on echocardiography. However, although we did not administer thrombolytics or pulmonary vasodilators, our patient's respiratory distress resolved with RT. This made us consider massive splenomegaly as the main etiologic factor. Remission of respiratory failure in relation with regression of massive splenomegaly supported our consideration. We suggest that diaphragmatic restriction due to massive splenomegaly should be considered an etiologic factor for respiratory failure and that this is considered an indication for RT.

\section{References}

1 Mesa RA: How I treat symptomatic splenomegaly in patients with myelofibrosis. Blood 2009;113:5394-5400.

2 Mesa RA, Tefferi A: Surgical and radiotherapeutic approaches for myelofibrosis with myeloid metaplasia. Semin Oncol 2005;32:403-413.

3 Guilpain P, Montani D, Damaj G, Achouh L, Lefrère F, Le Pavec J, Marfaing-Koka A, Dartevelle P, Simonneau G, Humbert M, Hermine O: Pulmonary hypertension associated with myeloproliferative disorders: a retrospective study of ten cases. Respiration 2008;76:295-302.

Kadri Atay

Department of Internal Medicine

Istanbul Medical Faculty, Istanbul University

Post Box

TR-34390 Sehremini/Istanbul (Turkey)

Tel. +90 212414 2000, Fax +90 2124142022

E-Maildr_kadrii@yahoo.com 